\title{
Unfamiliar Congener used as a Visual Attractor in Wild Caught and Domesticated Sea Bass (Dicentrarchus labrax) Placed in a T-Maze
}

\section{David Benhaïm $^{1 *}$, Marie-Laure Bégout ${ }^{2}$ and Béatrice Chatain ${ }^{3}$}

${ }^{1}$ LERMA, INTECHMER/CNAM, BP 324, 50103 Cherbourg Cedex, France

'Ifremer, Laboratoire Ressources Halieutiques, Place Gaby Coll, BP 7, 17137 L'Houmeau, France

${ }^{3}$ Station Expérimentale d'Aquaculture Ifremer, Laboratoire de Recherche Piscicole de Méditerranée, Chemin de Maguelone, 34250 Palavas-Les-Flots, France

\begin{abstract}
The present work compared wild-caught and domesticated sea bass juveniles swimming activity, exploration and visual attraction induced by an unfamiliar congener located behind a transparent wall at the end of one arm of a T-maze. This cognitive challenge was based on the hypothesis that placed into a novel and therefore stressful environment; the fish would adopt a gregarious behaviour even though they were not familiar with the present congener. Twenty individuals of similar size from both origins were individually tested. After a $5 \mathrm{~min}$ acclimatization period, the wall of the start-box was removed and the maze was filmed during $20 \mathrm{~min}$. Different swimming variables including angular velocity (Vang), total distance travelled (Dtot), velocity mean (Vel), time spent in Immobility (Im) were analysed from videos as well as the time spent in each of 6 virtual zones including the start-box zone (Start), the zone near the congener (ZCong), the zone opposite to ZCong (OpCong) and three other zones. Vang was higher in domesticated fish and Im higher in wild fish but fish from both origins spent most of the time in ZCong showing a similar visual attraction induced by an unfamiliar congener of similar size. Nevertheless, individual variability was shown, including fish choosing to shelter in Start and fish visually attracted to the congener but located in OpCong. These results demonstrated an impact of domestication on a few swimming activity characteristics but not on gregarious behaviour. The findings are discussed with focus on ecological and aquaculture concerns and their potential interest for future cognition-based experiments on this species.
\end{abstract}

Keywords: Domestication; Maze; Visual cue; Personality; Swimming activity

Abbreviations: Start: Start-Box; PostStart: Post-Start; ZCong: Zone Near the Congener; OpCong: Zone Opposite to the Congener; PreCong: Zone Located Near ZCong; Vang: Angular Velocity; Dtot: Distance Travelled; Vel: Velocity Mean; Im: Time Spent in Immobility

\section{Introduction}

The aquaculture sector is so recent that most cultured fishes might be rather considered as exploited captives and only a few of them would be on the threshold of becoming domesticated [1]. Indeed, farmed fishes are little changed from their wild ancestral form and could usually be returned to the wild. However, consistent differences between wild and domesticated fish have been reviewed by several authors [2-4]. Likely to be the first to be affected, behavioural traits are good indicators of the domestication process [5-8]. Among the most studied of all, antipredator behaviour has been shown to be very sensitive to artificial rearing [9-14], and swimming performances to be poorer in domestic stocks [15]. These differences between wild and cultured fishes may be partly explained by different previous experiences [16]. Farmed fishes are facing conditions that seem to be less challenging than natural habitats e.g. structurally simpler environments, food easy to catch and absence of predators but they also have to adapt to high densities, restricted space, artificial and uniform food, and quite frequent handling [17].

A way to identify differences between wild and domesticated fish i.e., to study the impact of domestication, is to examine their behavioural responses to a novel environment. Initial introduction into novel environments has been shown to produce in Zebrafish and other small teleost fish, behaviors consistent with predator evasion, fear, and/ or anxiety [18]. For example, environment such as a light/dark plus maze, based on the tendency of the fish to seek dark backgrounds (or avoid light backgrounds) in unfamiliar environments, can be used to study these behaviors $[18,19]$. This device enabled to show behavioural differences in Zebrafish lines including ZIRC, $\mathrm{AB}$ and WIK, the latter of which descends more recently from wild populations in India [20].

European sea bass (Dicentrarchus labrax) is a leading species in Mediterranean aquaculture that was recently domesticated. This explains why very little is known on effects of the early step of domestication or selection for growth apart from classical traits of commercial interest [21,22] and first attempts made to analyse behavioural responses to challenges in 12-24 months old fish $[23,24]$. The present work compared wild-caught and domesticated sea bass juveniles swimming activity, exploration in T-maze in which one unfamiliar congener of similar size was placed at the extremity of one of the two arms, behind a transparent Plexiglas ${ }^{\bullet}$ wall precluding olfactory cues. Because natural selection has ceased in the domesticated line, we postulated that innate predator vigilance in an unfamiliar environment could wane from this latter, leading to behavioural responses different from those of wild ones. We also intended to test the hypothesis of visual attraction on both fish origins induced by the unfamiliar fish after being placed into this novel and therefore stressful environment. Indeed, when stressed, a fish seeks either to shelter [25-27] or cover behind other group members to

*Corresponding author: David Benhaïm, LERMA, INTECHMER/CNAM, BP 324 , 50103 Cherbourg Cedex, France, Tel: 33-(0)2-33-88-73-38; Fax : 33-(0)2-33-8873-39, E-mail: david.benhaim@cnam.fr

Received January 15, 2013; Accepted January 23, 2013; Published February 03, 2013

Citation: Benhaïm D, Bégout ML, Chatain B (2013) Unfamiliar Congener used as a Visual Attractor in Wild Caught and Domesticated Sea Bass (Dicentrarchus labrax) Placed in a T-Maze. J Aquac Res Development 4: 169 doi:10.4172/21559546.1000169

Copyright: @ 2013 Benhaïm D, et al. This is an open-access article distributed under the terms of the Creative Commons Attribution License, which permits unrestricted use, distribution, and reproduction in any medium, provided the original author and source are credited. 
reduce the chance of being caught by a predator [28]. It has been shown that fish reduces neighbour distance to obtain easier information about whether other group members have detected a predator [29] and that social interaction plays an important and beneficial role i regulating the stress response in cohesive social species such as sturgeon Acipenser fulvescens [30]. Since sea bass in the wild, at the juvenile stage, is a demersal and gregarious species [31], it could respond similarly. Binary choice tests between familiar and unfamiliar congener were already performed on several fish species showing that they preferentially school with familiar individuals [32-37]. Here we intended to examine the attraction induced by an unfamiliar congener. On one hand, there is actually little direct evidence for shoal fidelity among wild fish [38-40], but on the other hand, in aquaculture, fish are somehow forced to shoal with unfamiliar fish because of the stock management that implies frequent size grading procedures accompanied with tanks population reorganization.

Thus the following questions were addressed:

(i) Are there differences in exploration and swimming activities between wild-caught and domesticated fish in a maze?

(ii) Are wild-caught and/or domesticated sea bass juveniles visually attracted by an unfamiliar congener?

\section{Material and Methods}

\section{Experimental animals and housing conditions}

Domestic sea bass were hatched at the farm Aquanord SA (France), transferred on February $23^{\text {rd }}, 2009$ to the experimental station of INTECHMER (Cherbourg) when they were 3 days old (D3) and grown in a recirculated system. All parameters were set according to the protocol used by Aquanord hatchery except for the temperature that was $15.2 \pm 0.5^{\circ} \mathrm{C}$. The temperature usually reaches $21^{\circ} \mathrm{C}$ in a sea bass hatchery but here it was intentionally maintained at a lower level to avoid creating large size differences with the wild stock that was thought to be captured later according to the natural hatching conditions.

Wild sea bass juveniles were captured off the Mediterranean coast of France (Harbour of Cap d'Agde, Southern France, 43 58' N; 03 $30^{\prime}$ $19^{\prime \prime}$ E). A whole school of 560 wild fish observed from the boat was collected at low depth $(280 \mathrm{~cm})$. Immediately after capture they were transported to the experimental station (INTECHMER, Cherbourg) where they arrived 24 hours later, on April $15^{\text {th }}$ [41].

Both fish origins (about 400 individuals each) were later grown in open water system in two separate $2 \mathrm{~m} 3$ tanks until the beginning of this experiment which started on March $28^{\text {th }} 2010$. At this date, domesticated fish were 390 days old. Wild-caught fish ages were determined on a 30-individual sample and were of similar age as domesticated fish [41]. During the experimental period, light regime was 16:8 LD (light onset at 06:00 U.T.+1). In both tanks, temperature, salinity and oxygen level were $($ Mean $\pm \mathrm{SD}), 15.4 \pm 0.3^{\circ} \mathrm{C}, 35.0 \pm 0.0 \mathrm{~g} \mathrm{~L}-1,5.6 \pm 0.3 \mathrm{mg} \mathrm{L}-1$.

Two days before the beginning of observations, wild and domesticated fish were anesthetized with 2-phenoxyethanol $(0.3 \mathrm{ml}$ L-1) and based on previous biometry data, 20 individuals from each origin were selected. Total length (mean $\pm \mathrm{SD}$ ) was $11.7 \pm 0.6 \mathrm{~cm}$ in domesticated fish and $11.7 \pm 0.5 \mathrm{~cm}$ in wild ones ( $\mathrm{t}$-test: $\mathrm{t}=0.02$, $\mathrm{P}=0.98$ ); weight was $16.7 \pm 3.7 \mathrm{~g}$ in domesticated fish and $15.3 \pm 2.7$ $\mathrm{g}$ in wild ones ( $t$-test: $\mathrm{t}=-1.33, \mathrm{P}=0.19)$. These individuals were placed in two $200 \mathrm{~L}$ tanks. Additionally, a stock of 400 domesticated fish of same age but from a different tank was used to select 30 individuals of similar size and weight $(11.8 \pm 0.9 \mathrm{~cm}, 16.4 \pm 2.3 \mathrm{~g})$. These fish were placed in a third $200 \mathrm{~L}$ tank. They were used as unfamiliar attractors in the experiment. The three tanks were supplied with water of identical characteristics as original tanks.

\section{Experimental setup}

Individuals were tested one by one in a maze constructed from opaque white plastic and transparent Plexiglas ${ }^{\oplus}$ (Figure 1). The start box $(20 \times 10 \mathrm{~cm})$ was separated from the rest of the maze by a removable opaque wall. At the end of each arm of the maze, two strictly waterproof compartments $(20 \times 15 \mathrm{~cm})$ were also separated by a not removable transparent wall. The maze which floor was made of transparent Plexiglas ${ }^{\oplus}$ was placed on an infrared waterproof casing $(1 \times$ $1 \mathrm{~m}$, Noldus, The Netherland) that enables to record videos at low light intensity and to improve video analysis. Shortly before observations, the maze was filled with water which level was maintained at $12 \mathrm{~cm}$. Temperature, salinity and oxygen level were verified before and after the end of observations performed on each fish and were respectively $16.0 \pm 0.5^{\circ} \mathrm{C}, 35.0 \pm 0.0 \mathrm{~g} \mathrm{~L}-1,7.8 \pm 1.5 \mathrm{mg} \mathrm{L}^{-1}$ before, $16.0 \pm 0.5^{\circ} \mathrm{C}$, $35.0 \pm 0.0 \mathrm{~g} \mathrm{~L}-1,7.3 \pm 1.2 \mathrm{mg} \mathrm{L}-1$ after. Digital camera (Imaging Source DMK 21AUO4) with a frame rate of $30 \mathrm{~Hz}$ and a resolution of $640 \times 480$ pixels was positioned at $77 \mathrm{~cm}$ above the water surface. Two $60 \mathrm{~W}$ light bulbs were horizontally placed on the walls located on the left and right sides of the infrared casing. They were located $100 \mathrm{~cm}$ above the infrared casing and provided an indirect and homogenous lighting on the maze. The light intensity measured at the water surface of the maze was 100 Lux.

\section{Experimental protocol}

Before the beginning of observations, the position of the unfamiliar congener was randomly determined for each individual on the left or right arm of the maze. The first tested fish was gently collected from the tank using a net and immediately placed in a bucket closed by a cover then placed in the maze start-box. After a $5 \mathrm{~min}$ acclimatization period, the wall was removed and the video capture started. The maze was filmed during $20 \mathrm{~min}$. In order to test all individuals, 4 days were required. On the first day, five domesticated fish were consecutively tested in the morning and five wild fish were tested in the afternoon. On the second day, this protocol was reversed and so on for the third and fourth days. The water was entirely renewed between wild and domesticated individual batches. The unfamiliar fish used as the

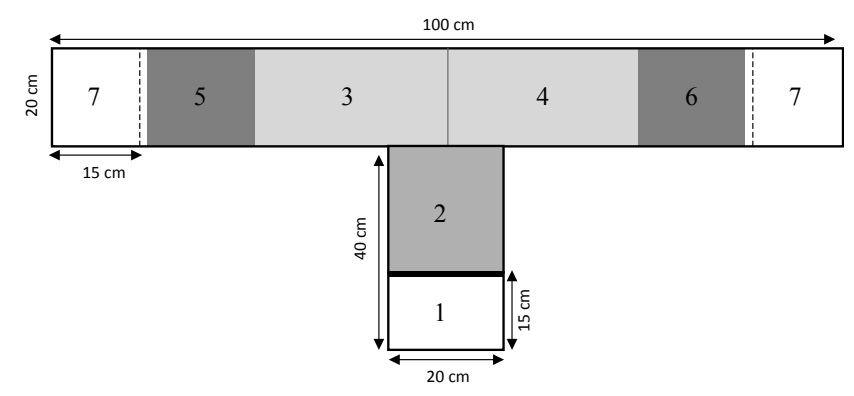

Figure 1: Schematic representation of the T-maze apparatus and virtual zones delimitation on the bottom of the maze defined for the video recordings analysis. Dotted lines are transparent Plexiglas $₫$ walls, continuous lines are white opaque plastic. The bottom of the maze is made of transparent Plexiglas ${ }^{\circledR}$.

1. Start-box closed by a removable opaque wall; 2 . Post-Start; 3 . Pre-left: area located on the right side of the left area; 4 . Pre-right: area located on the left side of the right area; 5 . left area located near the compartment where congener was placed; 6 . right area located near the compartment where congener was placed; 7. left and right compartments closed by a waterproof transparent Plexiglas ${ }^{\circledR}$ wall where congener was placed. 
attractor was changed every hour to minimize stress due to confinement and handling.

\section{Video analyses}

The video recordings were analysed using the software EthoVision XT 5 (Noldus, The Netherland), which allowed six virtual zones to be defined in the maze (Figure 1) and to track the fish swimming behaviour.

Each video was also viewed to measure the time spent oriented toward the congener vs. toward the empty compartment when the fish was located near the empty compartment (OpCong).

\section{Behavioural variables}

Different variables of interest were chosen to analyse the fish behaviour:

-The time spent in each zone expressed in seconds (s): Start-Box (Start), Post-Start (PostStart), zone near the congener (ZCong), zone opposite to ZCong (OpCong), zone located near ZCong (PreCong), zone located near OpCong (PreOpCong).

-The orientation toward the congener or toward the empty compartment when the fish was located in OpCong.

-The fish absolute angular velocity expressed in degree per second (Vang in ${ }^{\circ} \mathrm{s}^{-1}$ ) was calculated by the software as followed:

Vang $_{\mathrm{n}}=\mathrm{RTA}_{\mathrm{n}} / \mathrm{t}_{\mathrm{n}}-\mathrm{t}_{\mathrm{n}-1}$ where RTA $\mathrm{n}_{\mathrm{n}}$ is the relative turn angle for sample $n$ and $t_{n}-t_{n-1}$, the time difference between the current and previous sample. Here the rate of change in direction is unsigned. The turn angle is calculated as the difference between two subsequent values for head direction. This variable was an indicator of the amount of turning per unit time and quantified the swimming path complexity.

-The distance travelled by each fish in the maze (Dtot in $\mathrm{mm}$ )

-The velocity mean expressed in body length per second (Vel in BL s ${ }^{-1}$ )

-The time spent in immobility (Im in s)

The last three variables quantified the fish swimming activity level in the maze for each sequence.

\section{Statistical analysis}

All variables were compared using parametric analysis of variances (ANOVA) after verification of distribution normality and homoscedasticity [42]. When data did not fulfil these requirements, non parametric tests were used. Significant ANOVA were followed by a post-hoc multiple comparison test (Newman-Keuls). All statistical analyses were conducted using Statistica 8 (Statsoft, USA), and for all tests, the significant threshold was $\mathrm{p}<0.05$.

For the fish spatial distribution (time spent in each zone), since zones were not independent, ANOVA with Origin (wild and domesticated fish) as independent variable was performed for each of the three following zones: ZCong, OpCong, Start. Then a null model of space use was tested: the fish spatial distribution was compared to a theoretical homogeneous distribution in ZCong, OpCong and Start (12,5\% in each zone) by a Kolmogorov-Smirnov test. Other zones (PostStart, PreCong and PreOpCong), accordingly to their surfaces represented $75 \%$.

The time spent in ZCong was compared to time spent in Opcong in both fish origins using a Mann-Withney test.

The time spent oriented toward the congener zone was compared to the time spent oriented toward the empty compartment when the fish was located in OpCong using a Wilcoxon matched pair test inside each fish origin (wild and domesticated). The same comparison between wild and domesticated fish was done using a Mann-Whitney test.

Principal components analysis was used to search for individual variability in zone exploration among wild and domesticated fish.

All variables related to swimming activity were compared by ANOVA with fish origin (wild and domesticated) independent variable.

\section{Results}

\section{Spatial distribution}

All the fish tested left the start box after the wall was removed i.e. none of the fish spent $100 \%$ of the time in Start or in PostStart zones. Wild-caught and domesticated fish spent most of the time in ZCong (mean \pm SE, $41 \pm 7 \%$ and $38 \pm 8 \%$ respectively, Figure 2), the difference being not significant $\left(\mathrm{F}_{(1,36)}=0.11, \mathrm{P}=0.73\right)$. They also time spent similar times in OpCong $(20 \pm 5 \%$ in wild fish and $24 \pm 7 \%$ in domesticated ones, $\left.\mathrm{F}_{(1,36)}=0.21, \mathrm{P}=0.65\right)$. The observed fish spatial distributions were different from the theoretical homogeneous spatial distributions ( $\mathrm{D}=0.52, \mathrm{p}<0.01$ for ZCong, Opcong and Start).

When wild and domesticated fish were located in OpCong, they were oriented significantly more toward ZCong than OpCong ( $84 \pm 2 \%$ and $63 \pm 44 \%$ for wild and domesticated fish respectively, $\mathrm{Z}=2.3, \mathrm{P}=0.02$ in both cases) and there was no Origin effect for both orientations.

\section{Individual variability}

PCA showed that the first two components accounted for $94 \%$ of the variability of the data (Figure 3). The first component was related to two variables: the negative pole to high values of OpCong (contribution to the first component was 0.40 and the correlation was - 0.81 ), the positive one to high values of ZCong (contribution to the first component was 0.55 and the correlation was 0.94 ). As already shown in the previous section, PCA confirmed that most of the individuals were characterized by high values of ZCong (Figure 3) [43]. It represented 70\% of wild fish and $50 \%$ of domesticated ones. There were also $20 \%$ of domesticated fish and $15 \%$ of wild ones associated to high value of OpCong (Figure 3); $20 \%$ of domesticated fish and $5 \%$ of wild ones associated to high values of Start (Figure 3). At last, 10\% of wild fish associated to both Start and ZCong (W5 and W16, Figure 3 ) while $5 \%$ of both origins were associated to ZCong and OpCong (D11 and W8, Figure 3).



Start: Start Box, PostStart: area located after Start, ZCong: reward zone near the congene, OpCong: zone opposite to the reward zone, PreCong: zone located just before ZCong, PreOpCong: zone located just before OpCong.

Figure 2: Proportion of time spent (mean \pm S.E., in \%) by a fish in each zone of the maze. 


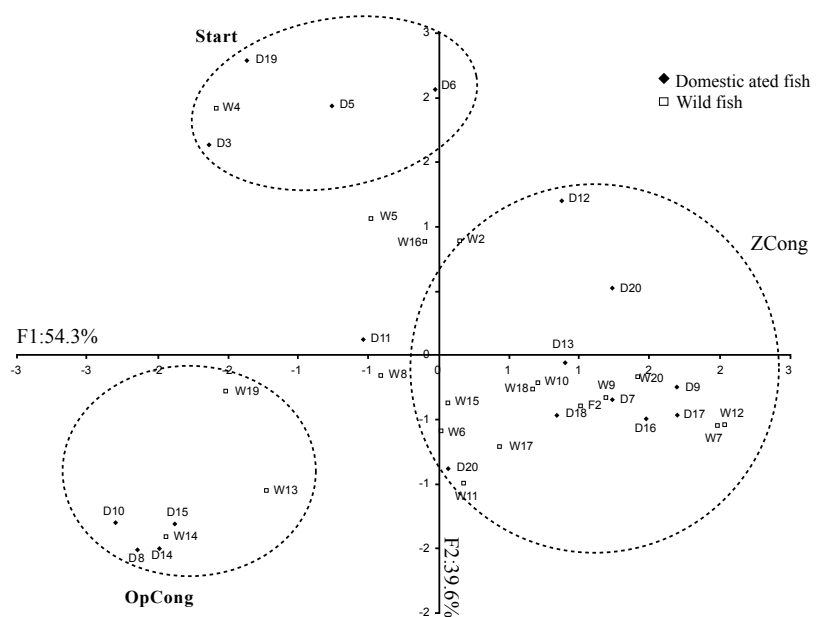

W: wild fish; D: domesticated fish; Start: Start Box; ZCong: zone near the congener, OpCong: zone opposite to ZCong.

Figure 3: Principal component analysis (PCA) applied to Zones explored in the maze.

\section{Swimming activity}

There was no difference for any swimming variables but Vang was higher in domesticated fish than in wild ones (mean \pm SE, $451 \pm 24$ and $335 \pm 36^{\circ} \mathrm{s}-1, \mathrm{~F}_{(1,38)}=6.4, \mathrm{P}=0.01$ ) and wild fish spent significantly more time immobile than domesticated ones (mean \pm SE, $73 \pm 13 \%$ and $68 \pm$ $16 \%$ respectively, $\left.\mathrm{F}_{(1,38)}=5.3, \mathrm{P}=0.02\right)$.

\section{Discussion}

The aim of this study was to assess for domestication effect on juvenile sea bass swimming activity, exploration and visual attraction to an unfamiliar congener. This was approached by comparing wildcaught and domesticated fish individually tested in a maze. The results showed a few behavioural differences between fish origins and a similar attraction to an unfamiliar congener.

A few behavioural differences were found between wild-caught and domesticated fish of similar size and age. Angular velocity was higher in domesticated fish, immobility higher in wild fish This difference between wild and domesticated fish demonstrated an impact of domestication on swimming activity. The difference in immobility could be linked to a decrease of the vigilance threshold [44] induced by the environment experienced by cultured fish that is strikingly different from that experienced by their wild counterparts e.g. the physical environment is much simpler, space is restricted and migration is not possible, it is less challenging in that good quality food is readily available and fishes are protected against predators $[2,5,45]$. On the contrary wild fish behaviour could indicate higher vigilance and then uncertainty in a novel environment such as a maze. Other studies on the same species have shown similar immobility differences between wild and domesticated fish at an early stage [41] and at a later stage [46]. In the present study, angular velocity was lower in wild fish than domesticated ones while the opposite tendency was observed in the previous cited studies. However, the values recorded in the present work were much lower than those recorded previously. Angular velocity difference between wild and domesticated sea bass has also been shown to be reversed in relation to aging [41]. In both cases, the fish remained motionless with its head oriented to the unfamiliar congener located behind the transparent wall.
Fish from both origins spent most of the time in the zone near the congener. This study demonstrated therefore a visual attraction in both wild-caught and domesticated fish induced by an unfamiliar congener of similar size. Placed into a novel and therefore stressful environment, fish from both origins seem to benefit from the presence of an unfamiliar congener which was associated with a decrease of the swimming activity. It could be related to the fact that social or gregarious species may greatly benefit from social interaction. Group behaviour has already been shown to increase growth as a result of social facilitation $[47,48]$ and to reduce predation risk [49]. The vigilance decreases when neighbour distance decreases because information about whether other group members have detected a predator is easier to obtain from nearer individuals [29]. Such gregarious behaviour is widespread among fishes, with many species forming non-random shoals according to species, size, parasite load and familiarity [39,50-54]. The present work showed that gregarious behaviour could also occur very fast even when fish are not with familiar conspecifics. In natural habitats shoals may encounter one another frequently, and field observations suggest that transfer of individuals between shoals may be substantial [38-40,55]. This reinforces the idea that the decision to shoal or not strongly depends on the context encountered by the fish which is in accordance with Hamilton's theory of the selfish herd [28]. For example, European minnows Phoxinus phoxinus shoal to obtain shelter, but only when there is insufficient physical structure available [56]. Placed in a T-maze without shelter, most of the tested individuals pitched on gregarious behaviour even though the congener was unfamiliar. This could be also linked to the fact that social interaction can play an important and beneficial role in regulating the stress response in cohesive social species [30]. Domestication did not impact this behaviour. However, some individuals from both origins spent more time on the opposite side of the congener but mostly oriented toward it while a few others spent most of the time in the start-box. Previous studies have shown that in accordance with the observed behaviour, individuals can be divided into coping style categories $[57,58]$ or been arranged along a behaviour gradient, such as the bold-shy continuum [59]. In the present work, a few individuals went out the start-box and decided thereafter to return to it where they remained till the end of video recording. It could be related to a shy personality trait and/or a subordinate status. Indeed, it is well known that staying alone could be a better strategy for subordinates [60] allowing them to have a lower probability of suffering injury in an escalated contest [61]. Fish that spent most of the time on the opposite side of the congener were visually attracted to the unfamiliar conspecific but made the choice to maintain maximum distance to it. Finally, individuals that spent the larger proportion of time near the congener could be considered as bold fish. However, this hypothesis needs to be confirmed by further research designed to test these behavioural tendencies in several contexts to match the definition of personality traits [62].

This preliminary experiment provided evidence for a gregarious behaviour in juvenile sea bass i.e. attraction to an unfamiliar congener, on the basis of visual cues alone. It also demonstrated individual variability including fish choosing to shelter in the start-box and fish visually attracted to the congener but maintaining maximum distance to it. These findings are in accordance with the life history of sea bass that develop a schooling life style at juvenile stage [63]. Domestication does not seem to impact this behaviour which is not surprising because farmed fish are often raised under high rearing density all along the production process and submitted to frequent population reorganization i.e. pooled with unfamiliar congeners. At the same time, swimming behaviour was impacted by domestication. 
Citation: Benhaïm D, Bégout ML, Chatain B (2013) Unfamiliar Congener used as a Visual Attractor in Wild Caught and Domesticated Sea Bass (Dicentrarchus labrax) Placed in a T-Maze. J Aquac Res Development 4: 169 doi:10.4172/2155-9546.1000169

These findings may have implications for restocking programs that often fail because of the dramatic level of mortality of newly released individuals [64] which are immediately placed in a novel and variable environment and exposed to predation risk [65]. The gregarious behaviour of domesticated fish in our study, similar to those of their wild-caught congeners may facilitate the fish shoaling (with unfamiliar congeners) when released in the wild which is crucial for predator avoidance. At last, these findings could also be useful to design cognition experiments on this species. Indeed, in these experiments, fish were trained to solve different tasks that were rewarded [66-68]. The use of an unfamiliar fish (on the basis of visual cues only) as a reward in such experiments seems to be particularly well adapted and more relevant than food.

\section{Acknowledgements}

We are grateful to Aquanord Company for providing domesticated animals and to AQUARID (Sète) for providing us with wild sea bass juveniles. This study was conducted under the approval of the Animal Care Committee of France under the official licence of M.L. Bégout (17-010).

\section{References}

1. Balon EK (2004) About the oldest domesticates among fishes. J Fish Biol 65: $1-27$.

2. Gross MR (1998) One species with two biologies: Atlantic salmon (Salmo salar) in the wild and in aquaculture. Can J Fish Aquat Sci 55: 131-144.

3. Ruzzante DE (1994) Domestication effects on aggressive and schooling behavior in fish. Aquaculture 120: 1-24.

4. Vandeputte $M$, Prunet $P(2002)$ Génétique et adaptation chez les poissons: domestication, résistance au stress et adaptation aux conditions de milieu. INRA Productions Animales 15: 365-371.

5. Price EO (1999) Behavioral development in animals undergoing domestication Appl Anim Behav Sci 65: 245-271.

6. Ruzzante DE, Doyle RW (1991) Rapid behavioral changes in Medaka (Oryzias Latipes) caused by selection for competitive and non competitive growth. Evolution 45: 1936-1946.

7. Ruzzante DE, Doyle RW (1993) Evolution of social behaviour in a resourcerich, structured environment: selection experiments with Medaka (Oryzias Latipes). Evolution 47: 456-470.

8. Swain DP, Riddell BE (1990) Variation in agonistic behavior between newly emerged juveniles from hatchery and wild populations of coho salmon, Oncorhynchus kisutch. Can J Fish Aquat Sci 47: 565-571.

9. Dellefors C, Johnsson Jl (1995) Foraging under risk of predation in wild and hatchery-reared juvenile sea trout (Salmo trutta L.). Nord J Freshw Res 70: 31-37.

10. Einum S, Fleming IA (1997) Genetic divergence and interactions in the wild among native, farmed and hybrid Atlantic salmon. J Fish Biol 50: 634-651.

11. Fernö A, Järvi T (1998) Domestication genetically alters the antipredator behaviour of anadromous brown trout (Salmo trutta)-a dummy predator experiment. Nord J Freshw Res 74: 95-100

12. Johnsson Jl, Abrahams MV (1991) Interbreeding with domestic strain increases foraging under threat of predation in juvenile steelhead trout (Oncorhynchus mykiss): an experimental study. Can J Fish Aquat Sci 48: 243-247.

13. Johnsson JI, Petersson E, Jönsson E, Björnsson B, Järvi T (1996) Domestication and growth hormone alter antipredator behaviour and growth patterns in juvenile brown trout, Salmo trutta. Can J Fish Aquat Sci 53: 1546-1554.

14. Jónsson B, Jónsson N (2001) Polymorphism and speciation in Arctic charr. $J$ Fish Biol 58: 605-638.

15. Beamish FW (1978) Swimming capacity. Book: Fish Physiology VII, Locomotion: 101-185.

16. Huntingford FA (2004) Implications of domestication and rearing conditions for the behaviour of cultivated fishes. J Fish Biol 65: 122-142.

17. FernöA, Huse G, Jakobsen PJ, Kristiansen TS (2007) The Role of Fish Learning Skills in Fisheries and Aquaculture. Blackwell Publishing Ltd: 278-310.
18. Gould GG (2011) Aquatic Light/Dark Plus Maze Novel Environment for Assessing Anxious Versus Exploratory Behavior in Zebrafish (Danio rerio) and Other Small Teleost Fish. Neuromethods 51: 99-108.

19. Serra EL, Medalha CC, Mattioli R (1999) Natural preference of zebrafish (Danio rerio) for a dark environment. Braz J Med Biol Res 32: 1551-1553.

20. Sackerman J, Donegan JJ, Cunningham CS, Nguyen NN, Lawless K, et al. (2010) Zebrafish Behavior in Novel Environments: Effects of Acute Exposure to Anxiolytic Compounds and Choice of Danio rerio Line. Int J Comp Psychol 23: $43-61$

21. Dupont-Nivet M, Vandeputte M, Vergnet A, Merdy O, Haffray P, et al. (2008) Heritabilities and GXE interactions for growth in the European sea bass (Dicentrarchus labrax L.) using a marker-based pedigree. Aquaculture 275 81-87

22. Vandeputte M, Baroiller JF, Haffray P, Quillet $E$ (2009) Amélioration génétique des poissons: quelles réalisations et quels défis pour demain ? Cahiers Agricultures 18: 262-269.

23. Millot S, Péan S, Chatain B, Bégout ML (2011) Self-feeding behavior changes induced by a first and a second generation of domestication or selection for growth in the European sea bass, Dicentrarchus labrax. Aquatic living resources 24: 53-61.

24. Millot S, Péan S, Leguay D, Vergnet A, Chatain B, et al. (2010) Evaluation of behavioral changes induced by a first step of domestication or selection for growth in the European sea bass (Dicentrarchus labrax): A self-feeding approach under repeated acute stress. Aquaculture 306: 211-217.

25. Bustard DR, Narver DW (1975) Aspects of the winter ecology of juvenile coho salmon (Oncorhynchus kisutch) and steelhead trout (Salmo gairdneri). Can J Fish Aquat Sci 32: 667-680

26. Cunjak RA (1988) Behaviour and microhabitat of young Atlantic salmon (Salmo salar) during winter. Can J Fish Aquat Sci 45: 2156-2160.

27. Greenwood MFD, Metcalfe NB (1998) Minnows become nocturnal at low temperatures. J Fish Biol 53: 25-32.

28. Hamilton WD (1971) Geometry for the selfish herd. Theor Biol Med Model 31 295-311.

29. Pöysä H (1994) Group foraging, distance to cover and vigilance in the teal, Anas crecca. Animal Behaviour 48: 921-928.

30. Allen PJ, Barth CC, Peake SJ, Abrahams MV, Anderson WG (2009) Cohesive social behaviour shortens the stress response: the effects of conspecifics on the stress response in lake sturgeon Acipenser fulvescens. J Fish Biol 74: 90104

31. Barnabé G (1989) L'élevage du loup et de la daurade. In Aquaculture G Barnabé coordonateur, Paris: Lavoisier-Tec Doc: 675-720.

32. Brown C, Laland KN (2002) Social learning of a novel avoidance task in the guppy: conformity and social release. Animal Behaviour 64: 41-47.

33. Brown GE, Smith RJF (1994) Fathead minnows use chemical cues to discriminate natural shoalmates from unfamiliar conspecifics. J Chem Ecol 20 3051-3061.

34. Farmer NA, Ribble DO, Miller DG (2004) Influence of familiarity on shoaling behaviour in Texas and blacktail shiners. J Fish Biol 64: 776-782.

35. Griffiths SW, Magurran AE (1997) Familiarity in schooling fish: how long does it take to acquire? Animal Behaviour 53: 945-949.

36. Miklósi Á, Haller J, Csányi V (1992) Different duration of memory of conspecific and heterospecific fish in the paradise fish (Macropodus opercularis L.) Ethology 90: 29-36.

37. Van Havre N, Fitzgerald GJ (1988) Shoaling and kin recongnition in the threespine stickleback (Gasterosteus aculeatus L.). Biological Behaviour 13 190-201.

38. Helfman GS (1984) School fidelity in fishes: The yellow perch pattern. Animal Behaviour 32: 663-672.

39. Hoare D, Ruxton GD, Godin JG, Krause J (2000) The social organization of free-ranging fish shoals. Oikos 89: 546-554.

40. Svensson PA, Balrber I, Forsgren E (2000) Shoaling behaviour of the twospotted goby. J Fish Biol 56: 1477-1487.

41. Benhaim D, Péan S, Lucas G, Blanc N, Chatain B, et al. (2012) Early 
Citation: Benhaïm D, Bégout ML, Chatain B (2013) Unfamiliar Congener used as a Visual Attractor in Wild Caught and Domesticated Sea Bass (Dicentrarchus labrax) Placed in a T-Maze. J Aquac Res Development 4: 169 doi:10.4172/2155-9546.1000169

life behavioural differences in wild caught and domesticated sea bass (Dicentrarchus labrax). Appl Anim Behav Sci 141: 79-90.

42. Dagnélie $P(1975)$ Théorie et méthodes statistiques. Applications agronomiques. Vol. II. Les méthodes de l'inférence statistique. Les Presses agronomiques, Gembloux: 463.

43. Zar JH (1984) Biostatistical analysis. In: (2ndedn.) Prentice Hall, Englewood Cliffs.

44. Bégout ML, Lagardère JP (2004) Domestication et comportement chez les poissons téléostéens. INRA Productions Animales 17: 211-215.

45. Waples RS (1999) Dispelling some myths about hatcheries. Fisheries 24: 12 21.

46. Millot S, Bégout M-L, Chatain B (2009) Exploration behaviour and flight response toward a stimulus in three sea bass strains (Dicentrarchus labrax L.). Appl Anim Behav Sci 119: 108-114.

47. Peuhkuri N, Ranta E, Sanna-Kaisa J, Lindstrom K (1995) Schooling affects growth in the three-spined stickleback, Gasterosteus aculeatus. J Fish Biol 46 221-226.

48. Stirling HP (1977) Growth, food utilization and effect of social interaction in the European bass Dicentrarchus labrax. Marine Biology 40: 173-184.

49. Roberts G (1996) Why vigilance decreases as group size increases. Animal Behavior 51: 1077-1086.

50. Griffiths SW (2003) Learned recognition of conspecifics by fishes. Fish and Fisheries 4: 256-268.

51. Griffiths SW, Ward AJW (2006) Learned recognition of conspecifics. In: Fish Cognition and Behaviour (eds.) C Brown, K Laland \& J Krause 139-165 Oxford: Blackwell.

52. Krause J, Godin JG, Brown D (1996) Phenotypic variability within and between fish shoals. Ecology 77: 1586-1591.

53. Krause J, Ruxton GD (2002) Living in groups. Oxford University Press.

54. Pitcher TJ, Parrish JK (1993) Functions of shoaling behaviour in teleosts. In Behaviour of Teleost Fishes (Pitcher, T J, ed), pp 363-439 London: Chapman \& Hall.

55. Hilborn R (1991) Modeling the stability of fish shools: exchange of individua fish between schools of skipjack tuna (Katsuwonus pelamis). Can J Fish Aquat Sci 48: 1081-1091.
56. Orpwood JE, Magurran AE, Armstrong JD, Griffiths SW (2008) Minnows and the selfish herd: effects of predation risk on shoaling behaviour are dependent on habitat complexity. Animal Behaviour 76: 143-152.

57. Koolhaas JM, Korte SM, De Boer SF, Van Der Vegt BJ, Van Reenen CG, et al. (1999) Coping styles in animals: current status in behavior and stressphysiology. Neuroscience \& Biobehavioral Reviews 23: 925-935.

58. Øverli Ø, Korzan WJ, Larson ET, Winberg S, Lepage O, et al. (2004) Behavioral and neuroendocrine correlates of displaced aggression in trout. Hormones and Behavior 45: 324-329.

59. Wilson DS, Coleman K, Clark AB, Biederman L (1993) Shy-Bold Continuum in Pumpkinseed Sunfish (Lepomis gibbosus): An Ecological Study of a Psychological Trait. Journal of Comparative Psychology 107: 250-260.

60. Ranta E, Rita H, Lindström K (1993) Competition versus cooperation: success of individuals foraging alone and in groups. American Naturalist 142: 42-58.

61. Abbot JC, Dunbrack RL, Orr CD (1985) The interaction of size and experience in dominance relationships of juvenile steelhead trout (Salmo gardneri) Behaviour 92: 241-253.

62. Sih A, Bell A, Chadwick Johnson J (2004) Behavioral syndromes: an ecological and evolutionary overview. Trends in Ecology \& Evolution 19: 372-378.

63. Barnabé G (1978) Etude dans le milieu naturel et en captivité de l'écoéthologie du Loup Dicentrarchus labrax (L.) (Poisson Serranidae) à l'aide de nouvelles techniques. Annales Sciences Naturelles, Zoologie, Paris, 12e série, 20: 423502

64. Olla BL, Davis MW, Ryer CH (1998) Understanding how the hatchery environment represses or promotes the development of behavioural survival skills. Bulletin of Marine Science 62: 531-550.

65. Brown C, Laland K (2001) Social learning and life skills training for hatchery reared fish. J Fish Biol 59: 471-493.

66. Huntingford FA, Wright PJ (1989) How sticklebacks learn to avoid dangerous feeding patches. Behavioural Processes 19: 181-189.

67. Odling-Smee L, Braithwaite V (2003) The role of learning in fish orientation Fish and Fisheries 4: 235-246.

68. Warburton K (2007) Learning of Foraging Skills by Fishes. Blackwell Publishing Ltd: 9-27. 